\title{
The Effects of Sintering Temperature and Pressure on the Sintering Behavior of Hydroxyapatite Powder Prepared by Spark Plasma Sintering*
}

\author{
Shufeng LI $^{* *}$, Hiroshi IZUI ${ }^{* *}$, Michiharu OKANO ${ }^{* * *}$ and Taku WATANABE** \\ "* College of science and technology, Nihon University, 7-24-1, Narashinodai, Funabashi, Chiba, \\ 274-8501, Japan \\ *** College of science and technology, Nihon University, 1-8-14, Kandasurugadai, Chiyoda, Tokyo, \\ 101-8308, Japan
}

\begin{abstract}
The sintering behaviors and resulting properties of hydroxyapatite (HA) were studied by employing Spark plasma sintering (SPS) process. An As-received HA powder was sintered and the sintering pressure was set as $22.3 \mathrm{MPa}, 44.6 \mathrm{MPa}$ and 66.9MPa respectively. At each pressure, the HA powder was sintered at different temperatures ranging from $800^{\circ} \mathrm{C}$ to $1000^{\circ} \mathrm{C}$ with a duration time of 8 minutes. The results showed that HA compact was rapidly densified to near theoretical density with the relative density of $99.1 \%$. The samples sintered at $44.6 \mathrm{MPa}$ possess higher flexural strength and Young's modulus than those at 22.3MPa. The flexural strength and Young's modulus achieved a maximum value of $123.2 \mathrm{MPa}$ and $75.2 \mathrm{GPa}$ respectively when the samples were sintered at $950^{\circ} \mathrm{C}$ and at pressure of $44.6 \mathrm{MPa}$. The external pressure accelerates the densification behaviors and overlade external pressure at $66.9 \mathrm{MPa}$ resulted in high residual stresses and thus deteriorated the mechanical properties. The XRD results indicated there was no decomposition of HA sintered at elevated temperature up to $1000^{\circ} \mathrm{C}$. The drop of mechanical properties was considered as the result of grain growth and hence residual stress induced microcracks.
\end{abstract}

Key words: Hydroxyapatite (HA), Spark Plasma Sintering (SPS), Sintering Pressure, Relative Density, Flexural Strength, Mechanical Properties

\section{Introduction}

The similarity in structure and composition of hydroxyapatite $\left(\mathrm{HA}, \mathrm{Ca}_{10}\left(\mathrm{PO}_{4}\right)_{6}(\mathrm{OH})_{2}\right)$ with the mineral phase of bone makes hydroxyapatite a promising biomaterials for implant[1]. Various forms of hydroxyapatite ceramics have been introduced as bone graft or regenerative therapy materials, such as dense HA, porous HA, HA based composites, as a coating on metallic implant and so on. Owing to the potential applications in skeletal reconstruction, the sintering of dense HA has attracted considerable attentions over the last two decades.

However, the relatively lower fracture toughness and flexural strength of bulk HA are the main obstacles which restrict its load bearing applications. Intensive research works have devoted to investigate the sintering behaviors and mechanical properties of densified HA by either conventional sintering processes[2-4] or new emerged spark plasma sintering process[5,6]. Mechanical properties are heavily dependent on sintering parameters such as temperature, pressure and so on. High temperature and pressure are necessary to 
accelerate densification of HA and thus may result in excellent mechanical properties. On the other hand, the nature of limited stability of HA undergoing thermal strategies should be elaborately considered to avoid the decomposition of HA within the temperature range of $1200-1400^{\circ} \mathrm{C}$ in $\operatorname{air}[3,7,8]$. Moreover, higher temperatures can result in coarser grain and higher pressure brings larger stress concentration, these are main problems which deteriorate the desired mechanical properties met in the conventional sintering methods. The novel spark plasma sintering (SPS) process has been developed during recent years. The outstanding advantages of SPS are the electrical energy supplied in combination with mechanical pressure which contributes to very short consolidation times, thereby preventing the formation of coarse grain size, in addition, the discharge plasma between the powder particles have a surface cleaning ability enhancing particle sinterability $[9,10]$. These advantages endue SPS process the ability to obtain fully dense samples at comparatively low sintering temperatures with excellent mechanical properties.

Various literatures concerned with the influences of temperature on sintering behaviors of HA, few contribute to study the effects of pressure on sintering behaviors and mechanical properties. The aims of present paper are to study the sintering behavior and optimum conditions of HA powder using SPS process. The effects of temperature and pressure on the properties of densified HA were assessed in terms of flexural strength, young's modulus and microstructure. The mechanism of sintering behavior was attempted to investigate explained from the point of view of densification behaviors and microstructure analysis. In addition, investigation from the point of influence of pressure induced stress and thermal expansion anisotropy on the mechanical properties was also conducted.

\section{Experimental procedure}

\subsection{Powder characterization}

A commercially available hydroxyapatite powder (Taihei Chemical, Japan) labeled as HA100 was used as the starting powder for this work. The phases present in the powder were identified by using a RINT $2000 \mathrm{x}$-ray diffractometer (Rigaku, Japan) with $\mathrm{Cu}-K_{\alpha}$ radiation source at $30 \mathrm{~mA}, 40 \mathrm{kV}$ with a scan speed of $0.5^{\circ} / \mathrm{min}$ and a scan step of $0.02^{\circ}$. Morphology of the powder precursor was also examined using a SS-550 scanning electron microscope (SEM) (Shimadzu, Japan) with an accelerating voltage of $25 \mathrm{kV}$.

\subsection{Sample preparation}

For sintering experiment, $4.5 \mathrm{~g}$ HA100 powder was loaded into a cylindrical graphite die and uniaxially compacted into green specimens by hydraulic pressure of 10MPa. Prior to this step, the interior surface of the die was sprayed with a layer of boron nitride film to lubricate and prevent the diffusion between graphite and hydroxyapatite at high temperature. The green compact was sintered in spark plasma sintering system DR.Sinter model SPS-3.2MK-IV (Sumitomo Coal Mining, Japan). Fig.1 shows a schematic of SPS system used in this study. The pressure was set as $22.3 \mathrm{MPa}, 44.6 \mathrm{MPa}$ and $66.9 \mathrm{MPa}$, respectively. The sintering temperature was in the range of $800{ }^{\circ} \mathrm{C}-1000^{\circ} \mathrm{C}$ with interval of $50^{\circ} \mathrm{C}$ at a heating rate of $100^{\circ} \mathrm{C}$ per minute at each sintering pressure. The vacuum level of the chamber was below $10 \mathrm{~Pa}$ during sintering. After holding at desired temperature for 8 minutes, the power was turned off and the sample was cooled in the chamber to less than $300^{\circ} \mathrm{C}$ with a cooling rate of $100^{\circ} \mathrm{C}$ per minute.

\subsection{Characterization of sintered HAp and mechanical testing}

The density of sintered samples was evaluated by both Archimedes' method using distilled water and geometrical method. The relative density was determined by taking the theoretical density of HA as $3.16 \mathrm{~g} / \mathrm{mm}^{3}$. Five measurements were conduct to obtain the average value. The crystal phases present in the sample were identified by $x$-ray diffraction 


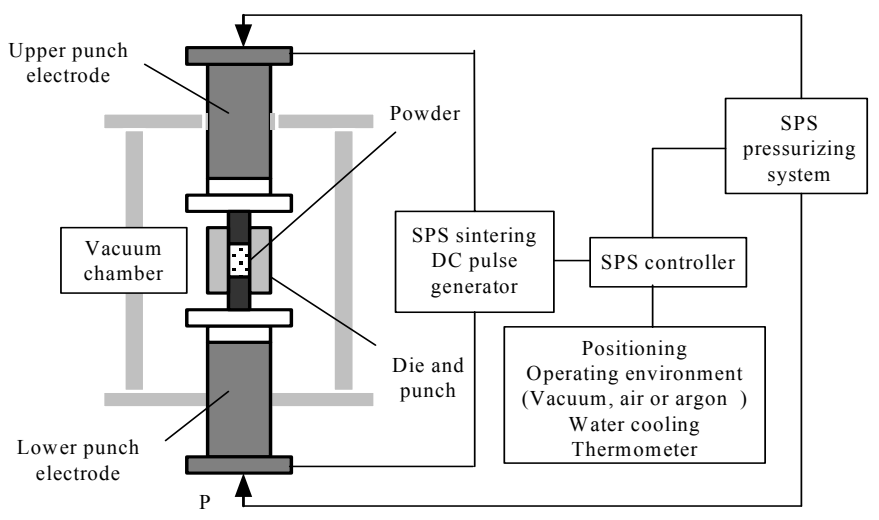

Fig.1. Schematic of typical spark plasma sintering (SPS) system and the graphite die used to fabricate samples by SPS

in reference to the standard ICDD PDF-2 cards available in the system software. In addition, microstructural evolution of dense samples including fracture surface as respect to various sintering temperatures was examined using SEM. The cross section of the samples were polished to $1 \mu \mathrm{m}$ surface finish using diamond paste and subsequently etched with $5 \%$ citric acid solution to reveal the grain boundaries. The flexural strength of sintered samples was measured by three-point bending test with Instron-5500R tensile tester (CA MA USA) using a cross-head with speed of $0.5 \mathrm{~mm} / \mathrm{min}$. Test plate with dimension of $56 \mathrm{~mm} \times 11 \mathrm{~mm}$ $\times 2 \mathrm{~mm}$ were ground and polished for three-point bending test. Five samples under same sintering conditions were prepared for bending test to give average value. The flexural strength was finally calculated based on the following equation:

$$
\sigma=\frac{3 P L}{2 b d^{2}}
$$

Where $\sigma$ denotes the flexural strength, $P$ denotes the applied load, and $L, b$ and $d$ are the span length, the width and the thickness of the specimen, respectively. Simultaneously, a strain gauge with $1 \mathrm{~mm}$ gauge length was glued on the opposite surface of the sample to monitor bending strain and the Young's modulus was calculated according to the following equation:

$$
E=\frac{L^{3}}{4 b d^{3}} \cdot \frac{\left(P_{2}-P_{1}\right)}{\left(\delta_{2}-\delta_{1}\right)}
$$

Where $E$ denotes the Young's modulus and other characters denote the same as those presented in equation (1).

\section{Results and discussion}

\subsection{Powder characterisation}

The XRD pattern of the starting HA powder is shown in Fig.2. All peaks perfectly matched with the ICDD PDF-2 pattern for HA which suggests that no other phases were present in the starting powder. The peak broadening which can be observed in Fig.2 is an indication of presence of submicron crystallite in the starting powder[11]. From these result it can be inferred that the starting powder was highly crystalline and composed of pure HA particles. SEM micrograph of the powder shown in Fig. 3 confirmed agglomerates were formed among primary particles, and the diameter of primary particle is approximately $0.2 \sim 0.3 \mu \mathrm{m}$ which was determined by the line intercept method. 


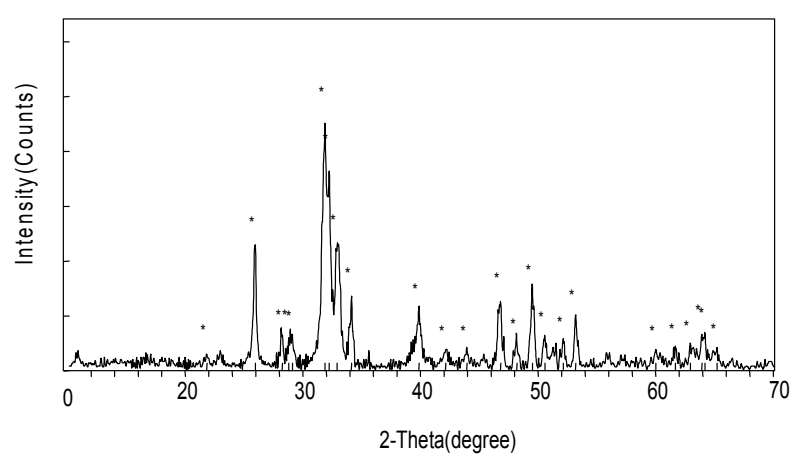

Fig.2. XRD pattern of as-received HA100 powder

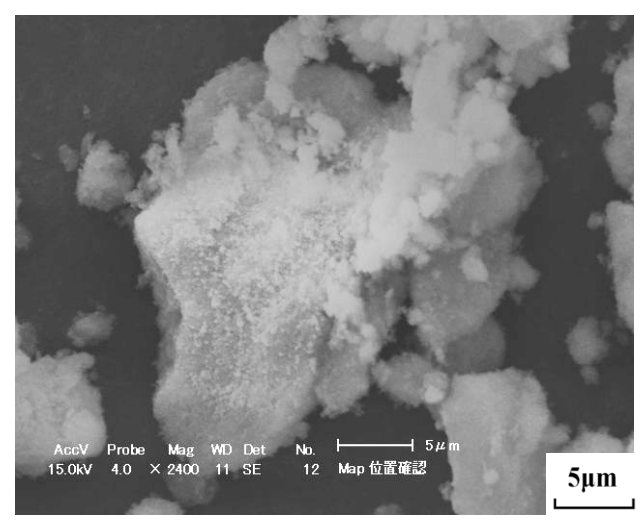

Fig.3. Scanning electron micrograph of the as-received HA powder

\subsection{Characterization of sintered HAp}

\subsubsection{Phase stability}

The XRD patterns of dense HA sintered at different temperatures at the pressure of 44.6MPa are shown in Fig.4. All peaks attribute to the HA phase. No additional peaks were observed at any sintering temperatures, the result indicated HA100 not decomposition sintered at elevated temperature up to $1000^{\circ} \mathrm{C}$ in vacuum using SPS. This is a little unconformity with those reported by Khor, K.A., the HA started to decompose when sintered at $1000^{\circ} \mathrm{C}[12]$. The difference possibly resulted from the differences of the starting powders, thermal strategies and so on even though using similar SPS process. The peak shift could be noted by comparing with the spectra of as-received HA powder. At low temperatures, the shift was considerable suggesting great lattice distortion [13]. it was reported that $\mathrm{HA}$ gradually lose the radical $\mathrm{OH}^{-}$(dehydroxylation) when it is heated to above $1100^{\circ} \mathrm{C}$ in air and $850^{\circ} \mathrm{C}$ in vacuum $[7,14,15]$, and $\mathrm{HA}$ molecules tend to lose lattice water gradually at high temperature to become $\mathrm{Ca}_{10}(\mathrm{PO} 4)_{6}(\mathrm{OH})_{2-2 \mathrm{x}} \mathrm{O}_{\mathrm{x}} \mathrm{V}_{\mathrm{x}}$ (V stands for vacancy) (OHA), which becomes $\mathrm{Ca}_{10}(\mathrm{PO} 4)_{6} \mathrm{O}(\mathrm{OA})$ above $1100^{\circ} \mathrm{C}$ [14]. And the formation of oxyapatite occurs according to the following equation:

$$
\mathrm{Ca}_{10}\left(\mathrm{PO}_{4}\right)_{6}(\mathrm{OH})_{2} \rightarrow \mathrm{Ca}\left(\mathrm{PO}_{4}\right)_{6}(\mathrm{OH})_{2-2 \mathrm{X}} \mathrm{O}_{X} \mathrm{~V}_{X}+\mathrm{XH}_{2} \mathrm{O}
$$

Where $\mathrm{x}$ is a non-charged vacancy and the lattice sites which were originally occupied by two $\mathrm{OH}$ groups in a HA unit cell, is now occupied by an oxygen atom while leaving the other vacant, which generally cause lattice contraction. 


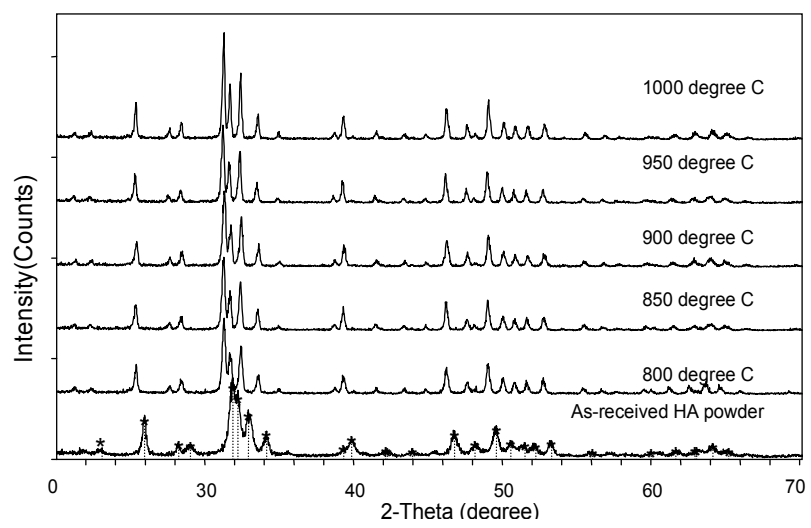

Fig.4. X-ray diffraction patterns of sintered samples at different sintering temperatures compared with as-received HA100 powder.

\subsubsection{Relative density}

The relative densities of sintered HA at different sintering pressures as a function of sintering temperature are shown in fig.5. It was found that the sintering temperature has an observable influence on the densification of HA. The relative density increased from $85.0 \%$ at $800^{\circ} \mathrm{C}$ to $99.1 \%$ at $1000^{\circ} \mathrm{C}$ at different sintering pressures. Sintering pressure improved the densification behaviors of $\mathrm{HA}$, for example, the density was increased from $85.0 \%$ at the pressure of $22.3 \mathrm{MPa}$ to $97.3 \%$ at the pressure of $66.9 \mathrm{MPa}$ at the same temperature of $800^{\circ} \mathrm{C}$. When the temperature was increased up to $900^{\circ} \mathrm{C}$, the relative density was increased up to $98 \%$, correspondingly, the density became nearly constant, i.e. the sintering temperature and pressure have limited influence on density. The sintered samples became transparent gradually with the elevated temperature, which also optically indicated the density increased rapidly with sintering temperature. The measured density is close to the theoretical value giving a maximum relative density of $99.1 \%$ at $1000^{\circ} \mathrm{C}$ at pressure of 66.9MPa. Compared to maximum densities achieved by conventional sintering methods reported in literatures[2, 7, 16], the sintering temperature was dramatically decreased by $200^{\circ} \mathrm{C} \sim 400^{\circ} \mathrm{C}$ in present study by using SPS.

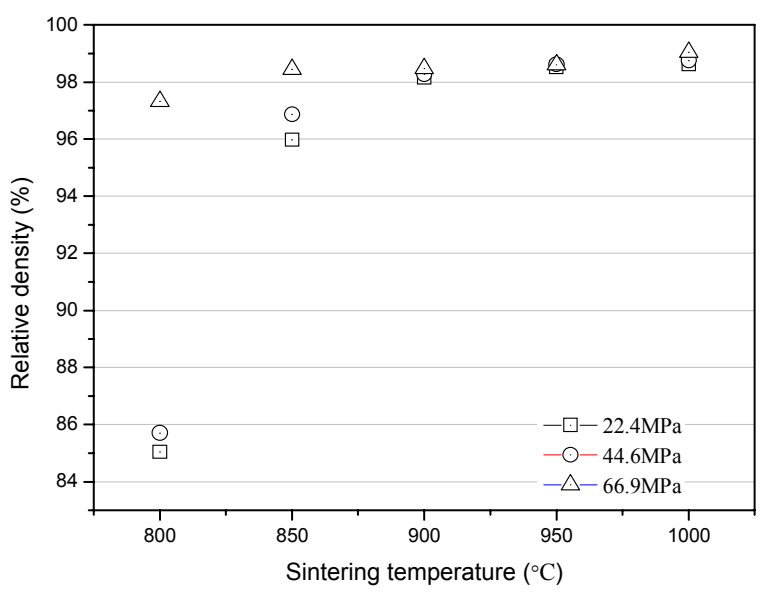

Fig.5. The relative density of sintered HA100 at different sintering pressures as a function of sintering temperature.

\subsubsection{Microstructural evolution}

The microstructures of polished and etched surface of HA sintered at pressure of $44.6 \mathrm{MPa}$ and $66.9 \mathrm{MPa}$ at different temperatures are shown in Fig.6. It can be found that at the initial stage of $44.6 \mathrm{MPa}$, the morphology shows an incompact structure, the pore is interconnected and unevenly distributed. When the sintering temperature increased up to 
$900^{\circ} \mathrm{C}$, slow grain growth was found to occur, the fracture surface reveals the cylindrical pores collapse into isolate spherical pores. The grain growth is evident when temperature increased up to $1000^{\circ} \mathrm{C}$, nearly no pores can be observed and the sintered body closed to the full density. The trend of densification is similar to the microstructures of HA sintered at pressure of $22.3 \mathrm{MPa}$. At the pressure of $66.9 \mathrm{MPa}$, evident grain growth is found to occur at $850^{\circ} \mathrm{C}$, and the grain size becomes coarse when sintering temperature reaches to $950{ }^{\circ} \mathrm{C}$.
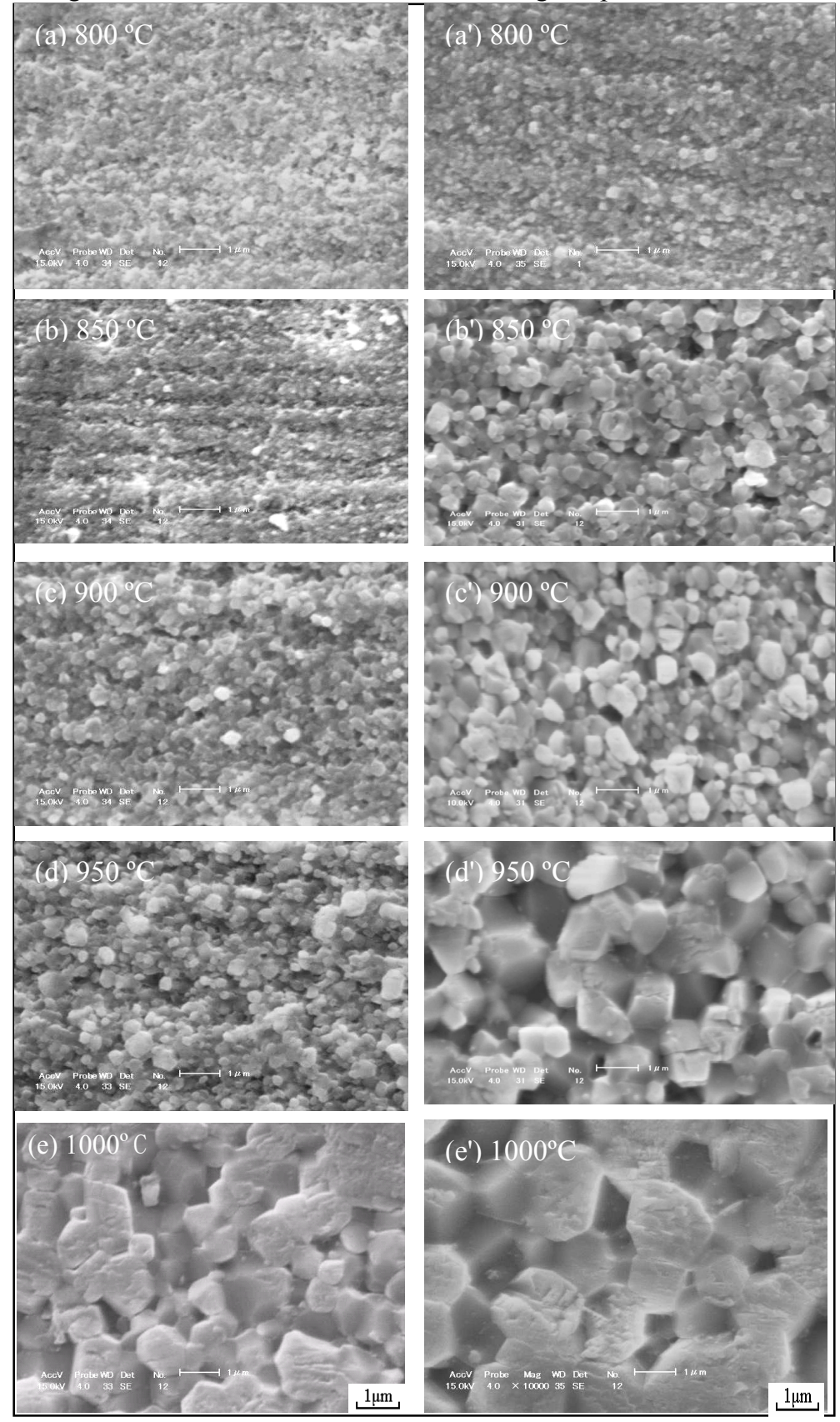

Fig.6. SEM micrographs of HA100 cross section surface sintered at various temperatures at the sintering pressures of $44.6 \mathrm{MPa}(\mathrm{a}) \sim(\mathrm{e})$ and $66.9 \mathrm{MPa}\left(\mathrm{a}^{\prime}\right) \sim\left(\mathrm{e}^{\prime}\right)$.

The variations of average grain size at different sintering temperatures are shown in Fig.7. It can be observed that the average grain size increased with increasing both temperature and pressure. The effect of the sintering temperature on grain size is only slight when the sintering temperature is lower than $950^{\circ} \mathrm{C}$ at the pressure of $22.3 \mathrm{MPa}$ and 44.6MPa. Distinct grain growth were found when temperature increased to $1000^{\circ} \mathrm{C}$. However, as the pressure was increased to $66.9 \mathrm{MPa}$, a comparatively rapid grain growth 
occurred. At low densification, where the relative density is lower than $85-90 \%$, grain growth is slow due to high volume fraction of the continuous/elongated pores throughout the compact. When the relative density is around $90 \%$, at which the continuous pores convert to isolated pores. The isolate pores are mobile, in contrast to the immobile continuous pores, lead to rapid grain growth[17]. From the results it can be inferred that application of higher external pressure result in rapid eliminating of pores and thus accelerating the grain growth.

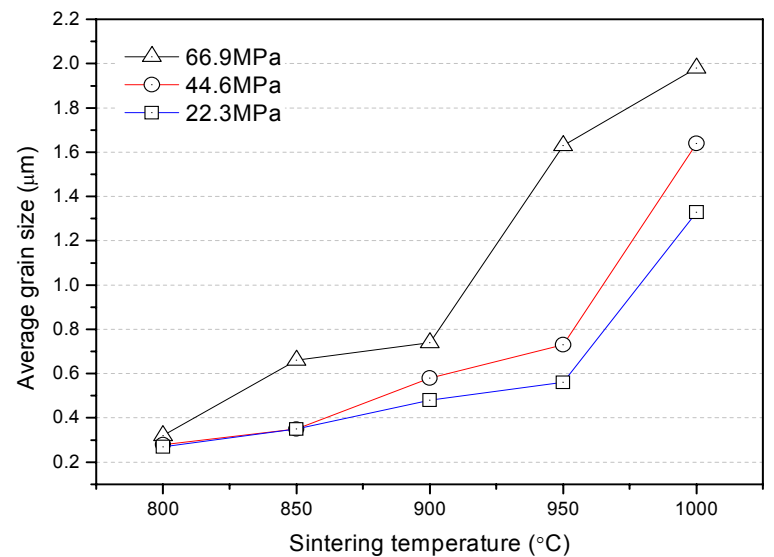

Fig.7. Average grain size of sintered HA100 at different sintering pressures as a function of sintering temperature

The densification behavior and grain growth progress at an accelerated rate at higher temperatures. The activation energy for grain growth was determined from the grain size measurements by plotting the logarithm of mean grain size against the reciprocal of the absolute temperature. The best fit line was plotted by using the least mean square method. The slope of this line was used to determine the activation energy from the following Arrhenius equation[17, 18].

$$
D_{t}^{n}-D_{0}^{n}=k_{0} t \exp (-Q / R T)
$$

where $D_{t}$ and $D_{0}$ are the grain sizes at time $t$, and $t=0$, respectively, $n$ is the grain growth exponent(n=2-4), $k_{0}$ is the pre-exponential constant of the diffusion coefficient, $Q$ is the activation energy for grain growth, $T$ is absolute temperature, and $R$ is the gas constant.

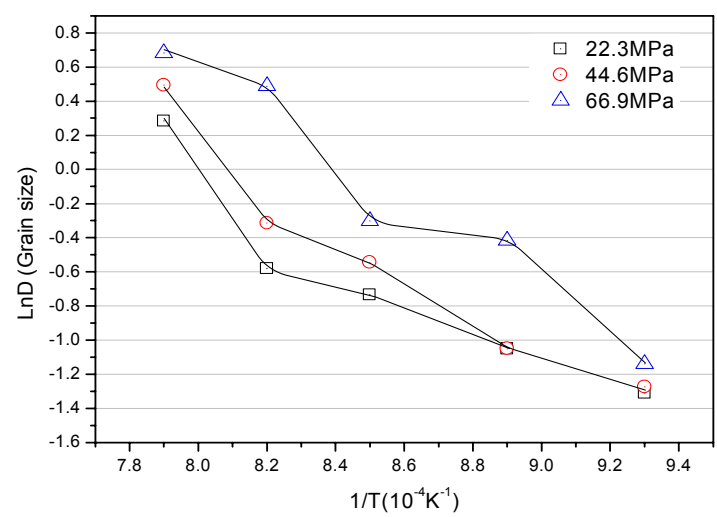

Fig.8. Arrhenius plot of natural logarithm of mean grain size versus reciprocal of sintering temperature at different sintering pressure

Fig.8 represents an Arrhenius plot of the variation of the logarithm of mean grain size as a function of the sintering temperature at different pressures. It can be observed from the figure that the trends of the curve variation are similar at sintering pressure of $22.3 \mathrm{MPa}$ and 44.6MPa. There are three stages, at temperature lower than $850^{\circ} \mathrm{C}$, grain size are small and 
grain growth are slow, particles begin to contact and grain boundary growth to replace the solid-vapor interface. This initial stage is characterized by rapid growth of the interparticle neck and surface diffusion dominates sintering at those low temperatures[19]. At temperatures of $850^{\circ} \mathrm{C}-950^{\circ} \mathrm{C}$, densification is accomplished by volume and grain boundary diffusion. Porosity is decreased and grain size is larger than the initial particle size obviously. By the final stage of sintering, the pore is spherical and closed, and grain growth is evident and the curve is steep. The slope of the plot allows calculation of the apparent activation energy for HAp diffusion at this temperature range, giving a value of $\mathrm{Q}=57 \mathrm{kcal} / \mathrm{mol}$ at $22.3 \mathrm{MPa}$ and $\mathrm{Q}=54 \mathrm{kcal} / \mathrm{mol}$ at $44.6 \mathrm{MPa}$, respectively. These value are in excellent agreement with those reported by Jarcho et al.(56 kcal $/ \mathrm{mol})[20]$ The curve at pressure of $66.9 \mathrm{MPa}$ is different with those at pressures of $22.3 \mathrm{MPa}$ and $44.6 \mathrm{MPa}$. The growth of the interparticle neck and grain boundary are accelerated by higher external pressure in the initial stage. This also proved by high relative density achieved and rapid grain growth. In the range at $850^{\circ} \mathrm{C}-900^{\circ} \mathrm{C}$, grain growth is becomes slow. The relative density is increased up to $98 \%$. Densification in the intermediate stage is accomplished by volume and grain boundary diffusion. Pores located on grain boundaries disappear more rapidly than isolate pores, surface transport is active during intermediate stage sintering as evident by pore rounding and pore migration with grain boundaries during grain growth, however, the surface transport processes do not contribute to densification or shrinkage[19]. When increase the temperature up to $950^{\circ} \mathrm{C}$, rapid grain growth is found and the activation energy at this temperature range giving a value of $\mathrm{Q}=52 \mathrm{kcal} / \mathrm{mol}$, this value is approximately equal to those at pressure of $22.3 \mathrm{MPa}$ and 44.6 MPa. The grain growth is become slow when increase temperature from $950^{\circ} \mathrm{C}$ to $1000^{\circ} \mathrm{C}$, the density is close to the theoretical density, thus there are fewer pores which are small and spherical. In the final stage of sintering, interaction between pores and grain boundaries can take three forms, the pores can retard grain growth, the pores can be dragged by the moving grain boundaries during grain growth, or grain boundary can break away from pores, leaving them isolated in the grain interior. At the typical sintering temperatures, most materials exhibit moderate to high grain growth[19]. As respect to present study, the sintering temperature to obtain fully dense samples at comparatively low sintering temperatures, typically $100^{\circ} \mathrm{C} \sim 400^{\circ} \mathrm{C}$ lower than in normal hot pressing [3, 20, 21].

\subsubsection{Mechanical properties}

The flexural strength and Young's modulus of HA compact as functions of sintering temperatures at different pressures are shown in Fig.9 and Fig.10, respectively. It can be observed that the general variation of the flexural strength and Young's modulus have the similar trends at pressure of $22.3 \mathrm{MPa}$ and $44.6 \mathrm{MPa}$, increased rapidly with sintering temperatures. The maximum flexural strength value of $123.2 \mathrm{MPa}$ and Young's modulus value of $75.2 \mathrm{GPa}$ were obtained for sample sintered at $950^{\circ} \mathrm{C}$ and pressure of $44.6 \mathrm{MPa}$. However, further increase in temperature up to $1000^{\circ} \mathrm{C}$ resulted in decrease in the flexural strength and Young's modulus both at $22.3 \mathrm{MPa}$ and $44.6 \mathrm{MPa}$. It can be observed the flexural strength and Young's modulus increased with the pressure increasing from $22.3 \mathrm{MPa}$ to $44.6 \mathrm{MPa}$ correspondingly. For samples sintered at pressure of $66.9 \mathrm{MPa}$, the values of flexural strength and Young's modulus are higher at the initial stage, saying in the range of $800^{\circ} \mathrm{C}-850^{\circ} \mathrm{C}$, continuing to increase the temperature up to $900^{\circ} \mathrm{C}$, the flexural strength and Young's modulus decrease distinctly with elevated temperature, which different with those at pressure of $22.3 \mathrm{MPa}$ and $44.6 \mathrm{MPa}$, although the density is increased slowly up to maximum value of $99.1 \%$ at $1000{ }^{\circ} \mathrm{C}$. The flexural strength of sample sintered at $850^{\circ} \mathrm{C}$ at pressure of $66.9 \mathrm{MPa}$ is close to the value sintered at $950^{\circ} \mathrm{C}$ at pressure of $22.3 \mathrm{MPa}$, it also indicate pressure and temperature have complementary effect in certain 
range.

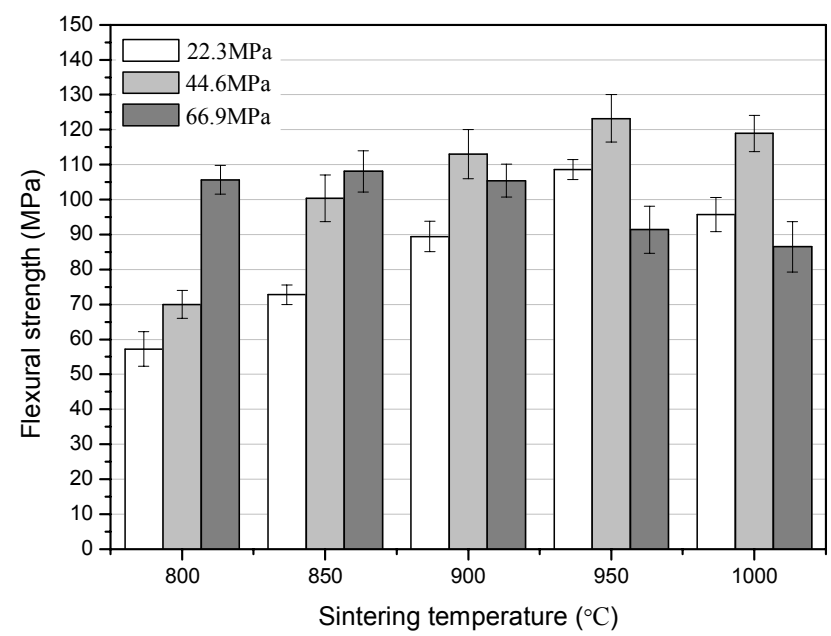

Fig.9. Flexural strength of sintered HA100 as a function of sintering temperature at different sintering pressures.

Decomposition of HA[3, 5], grain growth[16] and residual stress[22] are considered as the primary reasons for the decrease of mechanical strength of bulk HA. Since there was no decomposition of HA observed as shown in Fig.4 at present work, the exaggeration of grain growth and thermal expansion anisotropy induced residual stress are the main reasons which cause the decrease of mechanical strength of sintered HA. Hydroxyapatite crystallizes in a hexagonal lattice with spatial group $P 63 / m[23]$ and exhibits thermal expansion anisotropy, thermal expansion anisotropy results in contraction of individual grains from neighboring grains at differing rates, depending upon crystallographic direction. These differences in thermal contraction rates give rise to mechanical stresses[24]. If the differences in thermal contraction rates are large enough, thermal expansion anisotropy induced stresses can generate microcracks.

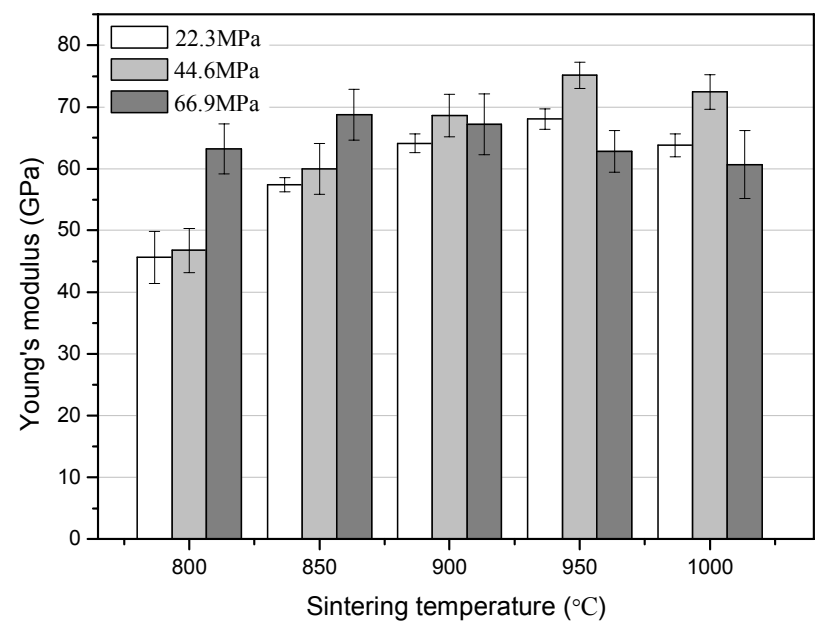

Fig.10. Young's modulus of sintered HA100 as a function of sintering temperature

at different sintering pressures.

The bulk density (or porosity) governs mechanical properties when the porosity is the dominant factor. When the bulk density increases close to the theoretical density, at present study, the bulk density is increased to $98.2 \%$ when sintering temperature increase to $900^{\circ} \mathrm{C}$ at $44.6 \mathrm{MPa}$, no significant increment can be made on the density further increasing the temperature and pressure as shown in Fig.5. The grain size becomes the dominant factor 


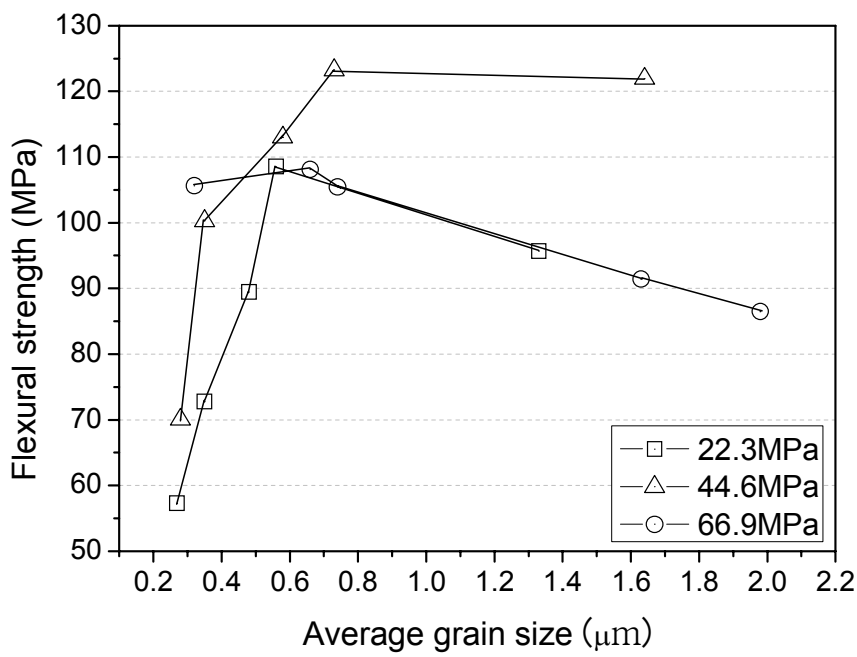

Fig.11. Flexural strength of sintered HA as a function of average grain size at different sintering pressures.

governing the mechanical properties instead of bulk density. According to the Hall-Petch equation[25],

$$
\sigma_{f}=\sigma_{0}+k d^{-1 / 2}
$$

where $\sigma_{f}$ is the fracture strength, $d$ is the grain size, $k$ and $\sigma_{0}$ are constants, and the strength decreases with increase grain size. The samples sintered at $950^{\circ} \mathrm{C}$ at pressure of 44.6MPa provide highest mechanical strength, heating over $950^{\circ} \mathrm{C}$ results in further grain growth and mechanical strength decrease. The grain size at this turning point is considered as critical grain size. This critical grain size is interrelated with thermal expansion anisotropy induced microcracking in brittle polycrystalline materials. If the grain size is larger than critical grain size, microcracking is easy to generate. The variation of flexural strength of dense HA as a function of average grain size at different sintering pressure is shown in Fig.11, the critical grain size is $0.56 \mu \mathrm{m}$ at $22.3 \mathrm{MPa}, 0.73 \mu \mathrm{m}$ at $44.6 \mathrm{MPa}$ and $0.66 \mu \mathrm{m}$ at $66.9 \mathrm{MPa}$. It can be found that the critical grain sizes are equal approximately at different pressures, while temperature is $850^{\circ} \mathrm{C}$ to reach critical grain size at $66.9 \mathrm{MPa}$ which is lower than those of $22.3 \mathrm{MPa}$ and $44.6 \mathrm{MPa}$. It was reported that the perpendicular section to the pressure direction showed larger crystallites size in the major axis than that of parallel section at high pressure. [26]. It indicates that thermal expansion anisotropy is facilitated by high pressure, stress is easy accumulate during cooling and thus resulted in decrease of mechanical properties. At present paper, microcracks can be observed transverse the grains marked by white arrow shown in Fig.12, the black arrow denote the fine pores located in the corner of grain boundary and the size is less than $0.5 \mu \mathrm{m}$. The critical grain sizes are in the range of $0.5-0.7 \mu \mathrm{m}$ with respect of different pressures.

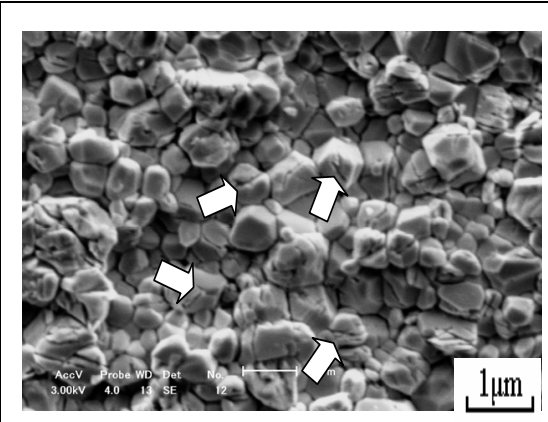

(a) $900^{\circ} \mathrm{C}, 66.9 \mathrm{MPa}$

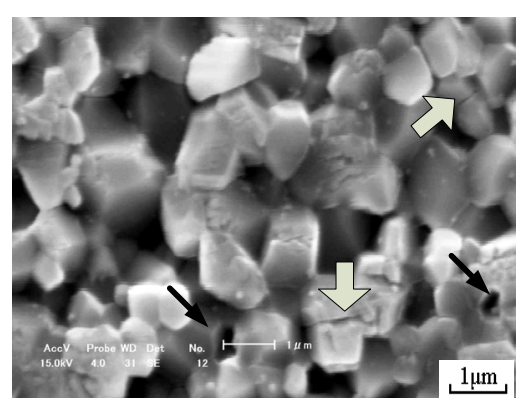

(b) $950^{\circ} \mathrm{C}, 66.9 \mathrm{MPa}$

Fig.12. SEM micrograph of as-sintered HA samples cross-section surface sintered at $950^{\circ} \mathrm{C}$ at pressure of $66.9 \mathrm{MPa}(\times 10000)$. 


\section{Conclusions}

HA powder was successfully sintered by spark plasma sintering. The sintering temperatures and pressures are varied to clarify the influence of temperature and pressure on the mechanical properties. The results are summarized as follows:

The density increases rapidly at elevated temperature and reach to maximum value of $99.1 \%$, which is closed to theoretical value. The grain size increases slowly at lower temperature. The external pressure accelerates the densification behavior, thus the grain growth is hastened at higher pressure compared with these at lower pressures. Overloaded external pressure result in high residual stress and thus deteriorate the mechanical properties.

There was no phase change in the samples sintered at temperature from $800^{\circ} \mathrm{C}$ to $1000^{\circ} \mathrm{C}$ for $8 \mathrm{~min}$. The grain size and residual stress are the main reasons which cause the decrease of mechanical strength of sintered HA. The critical grain size at present study is in the range of $0.5-0.7 \mu \mathrm{m}$ with respect of different pressures.

The optimum parameters for HA sintered by SPS are found to be $950^{\circ} \mathrm{C}$ and $44.6 \mathrm{MPa}$. The obtained properties at this condition are as follows: the maximum values of flexural strength and Young's modulus are $123.2 \mathrm{MPa}$ and $75.2 \mathrm{GPa}$ respectively, bulk density is $98.6 \%$ and the average grain size is $0.7 \mu \mathrm{m}$. The results show that the sintering temperature and pressure are critical factors influencing the densification behaviors, sintered microstructures and hence the mechanical properties such as flexural strength and elastic modulus.

\section{References}

[1] Murugan R, Ramakrishna S. Development of nanocomposites for bone grafting. Composites Science and Technology, vol.65, no.15-16, pp.2385-2406, Dec.2005.

[2] Akao M, Aoki H, Kato K. Mechanical-Properties of Sintered Hydroxyapatite for Prosthetic Applications. Journal of Materials Science, vol.16, no.3, pp.809-812, 1981.

[3] G.Muralithran SR. The effect of sintering temperature on the properties of hydroxyapatite. Ceramics International, vol.26, p.221-230. 2000.

[4] Landi E, Tampieri A, Celotti G, Sprio S. Densification behaviour and mechanisms of synthetic hydroxyapatites. Journal of the European Ceramic Society, vol. 20, no.14-15, pp.2377-2387, Dec.2000.

[5] Y. W. Gu, N. H. Loh, K. A. Khor, S. B. Tor, P. Cheang. Spark plasma sintering of hydroxyapatite powders. Biomaterials, vol.23, no.1, pp.37-43, Jan.2002.

[6] Hiroshi Izui, Michiharu Okano. Sintering and mechanical properties of hydroxyapatite by spark plasma sintering. Journal of the Science Society of Japan, vol.40, pp.52-57, 2003.

[7] Chunjen Liao, Fenghuei Lin, Koshao Chen, Juisheng Sun. Thermal decomposition and reconstitution of hydroxyapatite in air atmosphere. Biomaterials, vol.20, pp. 1807-1813, 1999.

[8] C. Kothapalli, M. Wei, A. Vasiliev, M. T. Shaw. Influence of temperature and concentration on the sintering behavior and mechanical properties of hydroxyapatite. Acta Materialia, vol.52, pp.5655-5663, Nov.2004.

[9] R. Kumar, P. Cheang, K. A. Khor. Spark plasma sintering and in vitro study of ultra-fine HA and ZrO2-HA powders. Journal of Materials Processing Technology, vol.140, pp.420-425, Sept.2003.

[10] M. Nygren, Z. J. Shen. On the preparation of bio-, nano- and structural ceramics and composites by spark plasma sintering. Solid State Sciences, vol.5, pp.125-131, Jan.2003.

[11] H.S. Liu, T.S. Chin, L.S. Lai, S.Y. Chiu, K.H. Chung, C.S. Chang, M.T. Lui. 
Hydroxyapatite synthesized by a simplified hydrothermal method. Ceramics International, vol.23, pp.19-25, 1997.

[12] K.A. Khor, Y.W. Gu, P. Cheang, F.Y.C Boey. The characteristics and properties of hydroxyapatite prepared by spark plasma sintering (SPS). Bioceramics, 15, vol.240-2, pp.497-500, 2003.

[13] Donglu Shi, Gengwei Jang, Jennifer Bauer. The effect of structural characteristics on the in vitro bioactivity of hydroxyapatite. Journal of Biomedical Materials Research. vol.63, pp.71-78, 2002.

[14] S.Dyshlovenko, L.Pawlowski. Modelling of plasma particle interactions and coating growth for plasma spraying of hydroxyapatite. Surface and Coatings Technology. vol.3, pp.3757-3769, 2006.

[15] B. Locardi, U. E. Pazzaglia, C. Gabbi and B. Profilo. Thermal behavior of hydroxyapatite intended for medical applications. Biomaterials, vol.14(6), pp.437-441, 1993.

[16] H.Y Juang, M.H Hon. Effect of calcination on sintering of hydroxyapatite. Biomaterials, vol.17, pp.2059-2064, Nov.1996.

[17] Rachman Chain. Densification mechanisms in spark plasma sintering of nanocrystalline ceramics. Materials Science and Engineering A. Vol.16, pp.25-32, 1981.

[18] Z. M. He, J. Ma, C. Wang. Constitutive modeling of the densification and the grain growth of hydroxyapatite ceramics. Biomaterials, vol.26, pp.1613-1621, 2005.

[19] R.M.German. Powder Metallurgy Science. Metal Powder Industries Federation, Princeton, NJ; pp.242-299, 1994.

[20] M. Jarcho, C. H. Bolen, M. B. Thomas, J. Bobick, J. F. Kay, R. H. Doremus. Hydroxylapatite Synthesis and Characterization in Dense Polycrystalline Form. Journal of Materials Science vol.11, pp.2027-2035, 1976.

[21] A. J. Ruys, M. Wei, C. C. Sorrell, M. R. Dickson, A. Brandwood, B. K. Milthorpe. Sintering Effects on the Strength of Hydroxyapatite. Biomaterials, vol.16, pp.409-415, 1995.

[22] Kobayashi S, Kawai W, Wakayama S. The effect of pressure during sintering on the strength and the fracture toughness of hydroxyapatite ceramics. Journal of Materials Science-Materials in Medicine, vol.17, pp.1089-1093, 2006.

[23] J.C.Elliott. Structure and chemistry of the apatites and other calcium orthophosphates. Amsterdam: elsevier science, pp.29-30, 1994.

[24] E.D. Case, I.O. Smith, M.J. Baumann. Microcracking and porosity in calcium phosphates and the implications for bone tissue engineering. Materials Science and Engineering A, Structural Materials Properties Microstructure and Processing; vol.390, pp.246-254, Jan.2005.

[25] http://www.matsci.ucdavis.edu/MatSciLT/EMS-174L/Files/HallPetch.pdf. Accessed 10 march 2007.

[26] Yujiro Watanabe, Toshiyuki Ikoma, Akira Monkawa, Yasushi Suetsugu, Hirohisa Yamada, Junzo Tanaka, Yusuke Moriyoshi. Fabrication of transparent hydroxyapatite sintered body with high crystal orientation by pulse electric current sintering. Journal of America Ceramics Society, vol.88 [1], pp.243-245, 2005. 